\title{
Metaphorical Visualization of Marginalized Groups in Advertisements and Its Impact on the Viewers' Responses
}

\author{
Wafa Chakroun ${ }^{1,2}$ \\ ${ }^{1}$ Institute of Higher Commercial Studies of Sfax (IHECS), University of Sfax, Sfax, Tunisia \\ ${ }^{2}$ Laboratory on Approaches to Discourse, Faculty of Letters, Arts and Humanities of Sfax, Sfax, Tunisia
}

\section{Email address:}

Wafa.chakroun@ihecs.usf.tn

\section{To cite this article:}

Wafa Chakroun. Metaphorical Visualization of Marginalized Groups in Advertisements and Its Impact on the Viewers' Responses. International Journal of Applied Linguistics and Translation. Vol. 7, No. 3, 2021, pp. 96-108. doi: 10.11648/j.ijalt.20210703.13

Received: July 25, 2021; Accepted: August 23, 2021; Published: August 31, 2021

\begin{abstract}
This study examines the use of visual metaphor on marginalized groups in print advertisements and its impact on the viewers' responses; namely, on the brand evaluation and on the viewers' negative emotions. To this end, a questionnaire was distributed to a sample of 70 respondents who saw four advertisements two of which included marginalized models without any visual metaphor cues, while in the two other commercials visual metaphors were added on the marginalized models. The main findings show that respondents reacted positively towards the use of marginalized models used without visual metaphor. However, their reactions were unfavorable and showed more negative emotions towards advertisements using metaphorical visualization on marginalized groups. These results highlight that diversity and non-standardization are welcomed in advertisements as long as the viewers' schemas are not violated. Put differently, viewers' negative emotions and unfavorable brand evaluation were due to the use of visual metaphor on marginalized groups which violated their schemas and evoked messages of racism, inequality and injustice. Henceforth, this study suggests that using visual metaphor on marginalized groups should be dealt with carefully, especially when companies aim to gain higher retention rate and brand awareness. Indeed, they should take into consideration several aspects such as historical, social, political and cultural factors when using visual metaphor on marginalized portrayals in order not to deviate the target audience.
\end{abstract}

Keywords: Visual Metaphor, Marginalized Groups, Advertisements, Viewers’ Responses

\section{Introduction}

Over many years marketers have created an idealistic world in their advertising messages in order to directly relate to customers' core beliefs, values and needs. These idealistic advertisement messages have often included beautiful, nice body-shaped models, happy parents, white-ethnic groups and healthy models. The main aim behind using this idealistic advertisement philosophy is to ensure a strong brand positioning and push consumers to purchase the product [16, 17, 19]. However, the development of technological devices and the evolution of many social norms have led to a shift in the way advertisements use models and ethnic groups. In fact, there is a remarkable increase in the appearance of fat, obese models, same-sex parents and black models in advertisements $[6,9]$. This new advertising trend attempts to make the brand an agent of political or social change by including non-traditional portrayals $[10,22,21]$. Although the use of visual metaphor in advertisements has been a fruitful topic for many researchers and has been widely studied in the literature, few articles and books have tackled the use of visual metaphor on marginalized groups [18]. Hence, this study attempts to investigate viewers' reactions towards the use of visual metaphor on marginalized groups; namely, on the viewers' negative emotions and on the way they evaluate the brand. In what follows, a literature review of metaphorical visualization on marginalized groups is presented.

\section{Literature Review}

This section aims to provide an overview of the literature 
on the use of visual metaphor on marginalized groups in commercials. It is divided into two main theoretical parts. The first part will focus on the concept of marginalization in advertisements and the second part will shed light on the use of visual metaphor on marginalized groups used in advertisements and its impact on the viewers.

\subsection{The Use of Marginalized Groups in Advertisements}

Despite the increase in the use of non-traditional portrayals in commercials, this trend has received relatively little scholarly attention [18]. According to several scholars, the recent use of marginalized groups in commercials aims to create engagement, to relate the brands to consumers' everyday conversation and to create change among certain societal norms and stereotypes $[6,11,22]$. According to [2], the presence of African-American models, which are considered non-traditional portrayals, is mainly restricted to clothes, shoes and accessories, while their presence in business and work-related setting is very low. Furthermore, [3] relate the use of marginalized groups in advertisements to purchase activism which refers to the desire to purchase items from brands that hold the same buyers' values. Indeed, the concept of purchase activism reflects the new societal trends of helping others, fight against discrimination, racism and gender stereotypes. It has been shown that purchase activism positively influences consumers' willingness to purchase the brand [7]. Moreover, purchase activism has been related by several scholars to the schema concept which refers to the stored framework, knowledge and cues that stand for a specific topic of a specific group of people [8]. In the case of advertising, the cues are intended to trigger schemas which are related to the target viewers' background and preferences. Previous studies found that when an advertisement includes cues which are inconsistent with the viewers' schemas, it may lead to a negative reaction towards the brand [4]. Other studies have shown that the use of nontraditional groups can lead to positive reactions and encourage viewers to purchase the brand $[1,18]$. In this context, it was shown that advertisements picturing homosexual parents, for example, elicit two contradictory reactions [16]. On the one hand, these commercials lead to positive reactions by enhancing recall and attention as viewers develop higher brand retention and awareness. On the other hand, these advertisements require higher cognitive efforts because they contain portrayals which are inconsistent with the viewers' existing schemas which lead to negative responses [1]. More importantly, the relation between viewers' schemas and the use of marginalized groups in advertisements was deeply studied in [18] research which focused on the viewers' reactions towards the use of marginalized groups by using print advertisements of the breakfast cereal brand "Cherrios" and the water drink brand "Dasani". Each brand used two different advertisements with two different schemas. Cherrios commercials are shown in figures 1 and 2 .

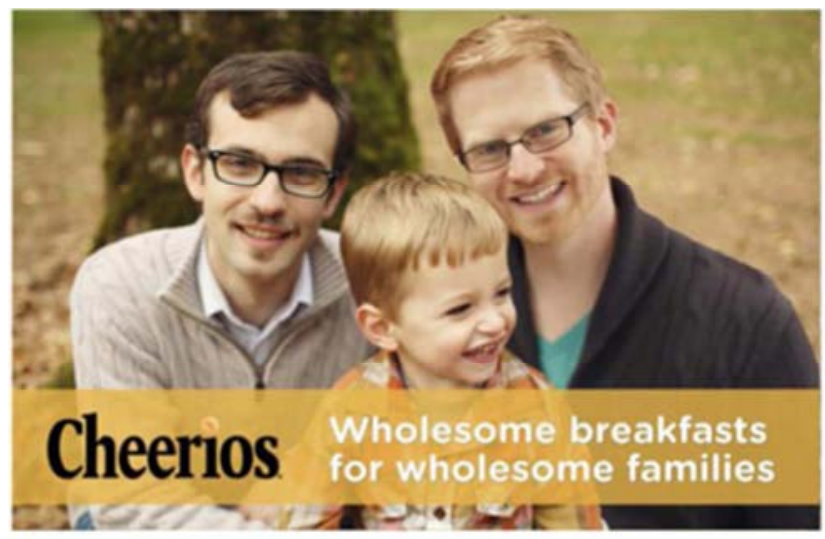

(Ruggs et al. 2018, p. 15)

Figure 1. The use of same-sex parents (marginalized group) in Cherrios brand.

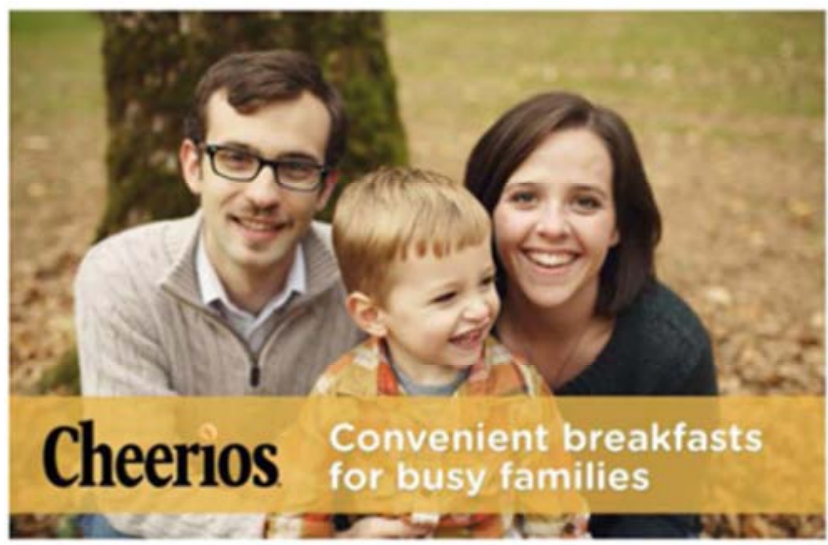

(Ruggs et al. 2018, p. 15)

Figure 2. The use of hetero-sexual parents (traditional group) in Cherrios brand.

Cherrios first advertisement, as shown in figure 1, uses same sex parents (marginalized group) with a slogan saying "wholesome breakfasts for wholesome families". The second advertisement, which is illustrated in figure 2, employs hetero- sexual parents with the slogan of "convenient breakfast for busy families". The study participants, who were hetero-sexual couples, showed two different reactions towards the two commercials. In fact, couples with children showed less favorable brand evaluation to the same-sex parents when the schema of "wholesome families" was activated, whereas couples without children responded more favorably to the same-sex parents with "wholesome families" schema. However, the schema "busy family" elicited more favorable brand evaluation from couples with children than couples without children. This finding highlights the fact that viewers welcome the use of marginalized groups and showed higher purchase activism when they saw same-sex parents. This positive attitude, however, was relevant only when the advertisement was consistent and did not violate the viewers' schemas. The relation between viewers' schemas and marginalized groups is also shown in Dasani brand which is shown in figures 3 and 4 . 


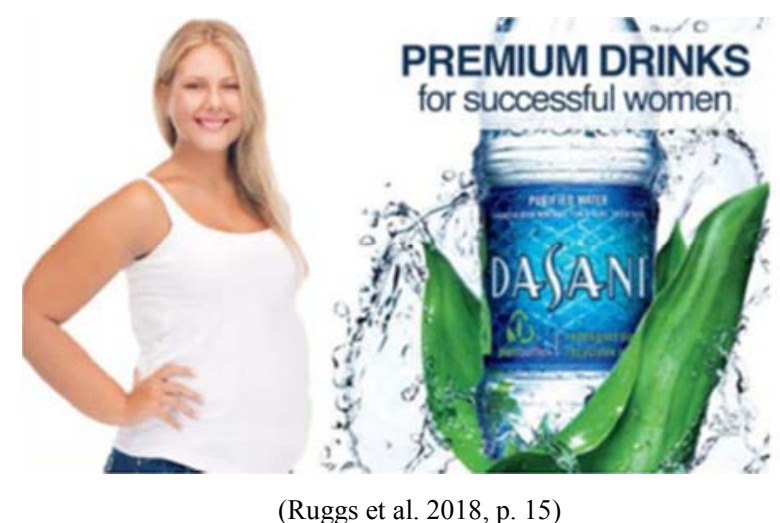

Figure 3. The use of fat model (marginalized model) in Dasani brand.

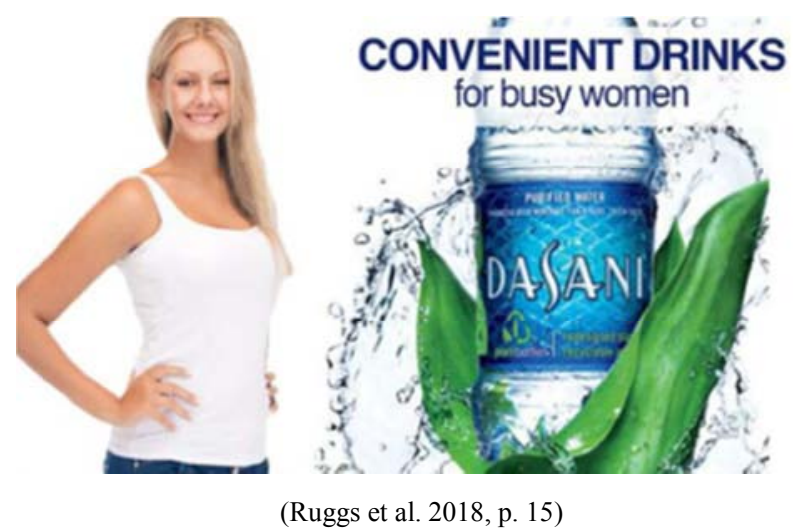

Figure 4. The use of thin model (non-marginalized model) in Dasani brand.

Figure 3 shows a fat woman representing marginalized portrayal in Dasani brand versus a thin model, as shown in figure 4, representing non marginalized model. The brand uses two slogans: "Premium drinks for successful women" and "convenient drinks for busy women". The experiment findings show that female viewers' evaluated the overweight model less favorably than the thin model when the schema of "successful woman" was activated. However, the overweight model gathered more favorable brand evaluation than the thin model when the schema of "busy woman" was activated. More interestingly, female viewers evaluated the two models in the same way when the schema of "active woman" was activated. When the schema of "successful woman" was activated, the overweight model generated more negative emotions compared to thin model. Male viewers evaluated the two models similarly regardless of which schema was activated. These findings show that the use of marginalized models has an effect on the viewers' reaction towards the brand, especially when other factors come into play, namely the viewers' schemas. Put differently, if the advertisement goes in the same line with the viewers' schemas, viewers will express more favorable brand evaluation and positive emotion towards the brand. They will react positively to most marginalized portrayals as long as their schemas are not violated. Based on the claims above, the two hypotheses are as follows:

H1: The use of marginalized groups in print advertisements has a positive effect on the brand evaluation.
H2: The use of marginalized groups in print advertisements has a positive effect on the viewers' emotions.

\subsection{Metaphorical Visualization of Marginalized Groups in Advertisements}

Besides the use of marginalized groups in advertisements, some brands use visual metaphor in order to create greater impact. According to [13], visual metaphor has been considered as an indirect claim as it does not offer a direct message but requires the viewer to understand visual metaphor by using visual cues. Those visual cues are presented in the language of pictures. More importantly, it has been shown that the use of visual metaphor in print advertisements has a positive impact on the viewers' comprehension, attitudes and cognitive processing [14, 15]. However, the use of visual metaphor in print advertisements on marginalized groups has not been studied in previous studies and is still considered inexistent. Therefore, this study assumes the following hypotheses:

H3: The use of visual metaphor on marginalized groups has a positive effect on brand evaluation.

H4: The use of visual metaphor on marginalized groups has a positive effect on the viewers' negative emotions.

\section{Methodology}

This section focuses on the methodological procedures used in this research. It presents the data collection, the measurement procedures and the data analysis.

\subsection{Data Collection}

A sample of 70 students majoring in English was used to collect the data. The first step in collecting the data consisted in asking the participants to see two advertisements using non-traditional models and then to answer the questions of the first part of the questionnaire (see appendix). In the second step, the researcher used the same advertisements after adding metaphorical visualization and asked the participants to answer the second part of the questionnaire (see appendix). The four advertisements used to collect the data are shown below.

\subsubsection{Advertisements Using Marginalized Groups}
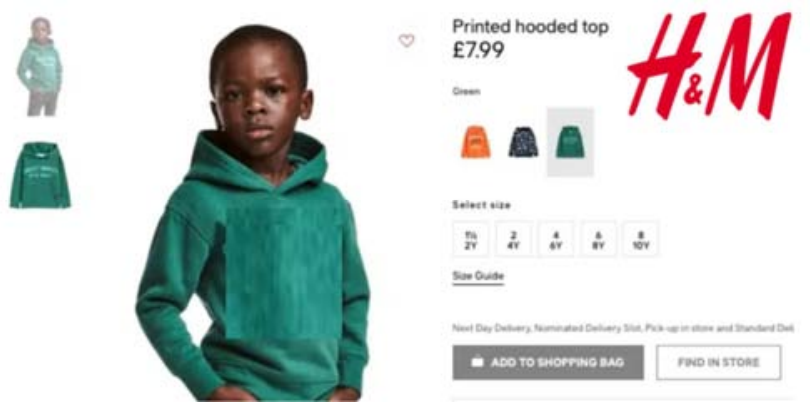

Figure 5. H\&M advertisement.

Retrieved from: https://www.thetimes.co.uk/article/shops- 
attacked-in-south-africa-over-h-m-monkey-ad-cd8cw89qt.

Figure 5 shows a black boy advertising for H\&M T-shirt. The model used in this commercial is considered a nontraditional model because international brands used to recruit white models for their commercials. This idea has been changed among many brands which are directing their attention towards marginalized models in order to become socially responsible and be an agent of change within society.

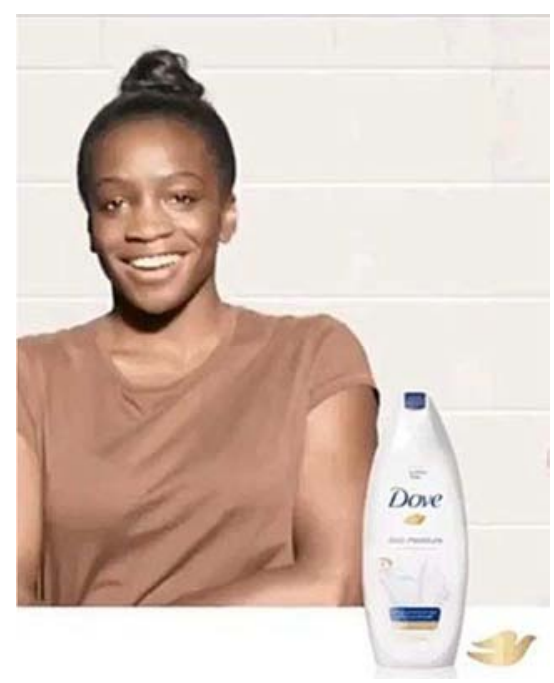

Figure 6. Dove advertisement.

Dove advertisement uses a black and fat model which contradicts with previous norms in which women model in advertisements used to be white, thin and well dressed.

\subsubsection{Advertisements Using Visual Metaphor on Marginalized Models}
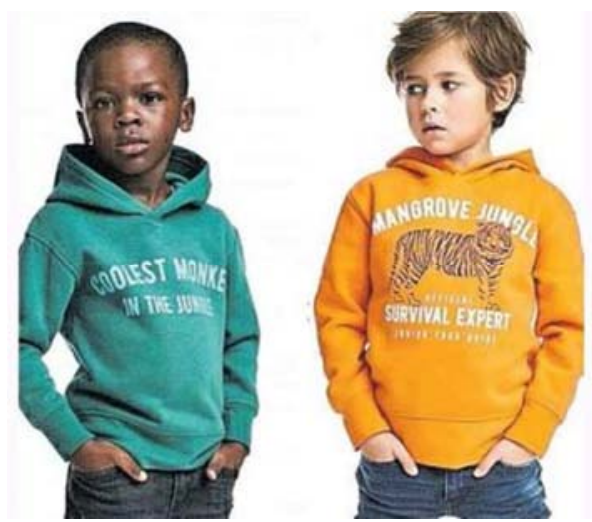

Figure 7 The use of visual metaphor on marginalized model in H\&M advertisement.

Retrieved from: https:/www.thetimes.co.uk/article/shopsattacked-in-south-africa-over-h-m-monkey-ad-cd8cw89qt.

Figure 7 shows the original advertisement used by H\&M to promote its new kid collection. The commercial uses a black boy, who represents the non-traditional portrayal and a white boy. The use of visual metaphor lies in the use of the slogan on the black boy's T-shirt: "the coolest monkey in the jungle", while on the white boy's T-shirt, H\&M uses the slogan of "Mangrove jungle, survival expert". In fact, the use of visual metaphor in H\&M advertisement associates the back boy with attributes of ugliness, weakness, fun, etc. The white boy, however, represents power, beauty, intelligence and expertise. The second advertisement using marginalized model concerns Dove brand which is shown below.

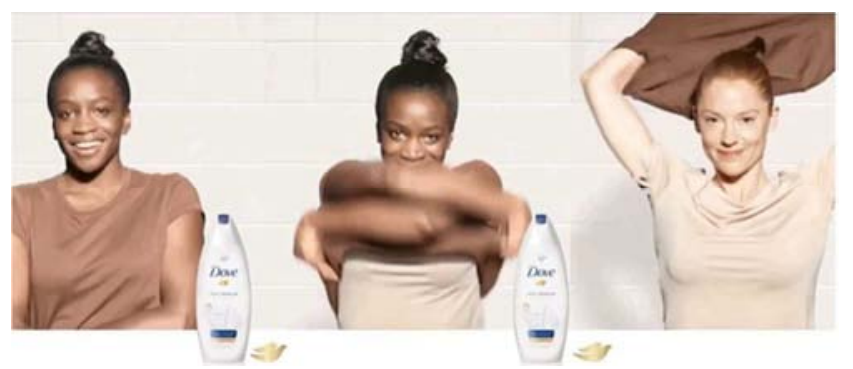

Figure 8. The use of visual metaphor on marginalized model in Dove advertisement.

Retrieved from:

https://www.thedrum.com/news/2017/10/12/will-dove-spepsi-moment-affect-the-brand-the-long-term.

Figure 8 shows Dove commercial; more specifically, the effect of Dove on the skin. It uses a black and a white model to emphasize the idea of the before and after usage. In this advertisement, the black and fat model is associated with dirt, ugliness and impurity. The white and thin model, however, represents beauty, cleanliness and purity. Henceforth, the use of visual metaphor in this advertisement lies in the before and after effect of Dove shower gel product.

\subsection{Measurement Procedures}

Participants viewed the 2 advertisements featuring marginalized models without any cues, slogans or metaphorical visualization (Figures 5 and 6). Then, the same participants observed the same advertisements but after adding the visual metaphor on the models (Figures 7 and 8). After viewing the commercials, participants completed a three-item measurement of the brand evaluation concept using 7-point scales. Participants rated the extent to which the ad (1) changed their interest in buying the product ( $1=$ low interest, $7=$ high interest), (2) affected their opinion about the brand ( $1=$ very bad, $7=$ very good), and (3) whether they liked the advertised brand ( $1=$ dislike very much, $7=$ like very much). Negative emotions were measured by asking participants to rate the extent to which they felt the following eight emotions after viewing the ad: disgusted, angry, revolted, irritated, accepting, happy, affectionate, and pleased (the last four items used a reversed score; ranged from 1=not at all to $7=$ very much) (Bhat et al. 1998).

\subsection{Data Analysis}

The data analysis deals with the manipulation of the data using the statistical software SPSS 20. The first part in the data analysis consists in factor analysis which tests the reliability and internal consistency of the items that form the concepts; namely, brand evaluation, negative emotions. The second part focuses on testing the hypotheses by running a 
paired sample t-test in order to show the means difference between the two types of advertisements. In other words, the means difference between commercials using only marginalized models versus commercials using metaphorical visualization on marginalized models.

\subsection{Factor Analysis}

The factor analysis consists in measuring the internal consistency and cohesion of the items forming the concepts of brand evaluation and negative emotions. The former concept included three items, whereas the latter concept contained 8 items. The main indices used in factor analysis were KMO coefficient, Bartlett's test, eigenvalue and Cronbach's alpha [12], The results of the factor analysis are shown in the table below.

Table 1. Factor analysis results.

Advertisement 1: H\&M and Dove advertisements using marginalized models

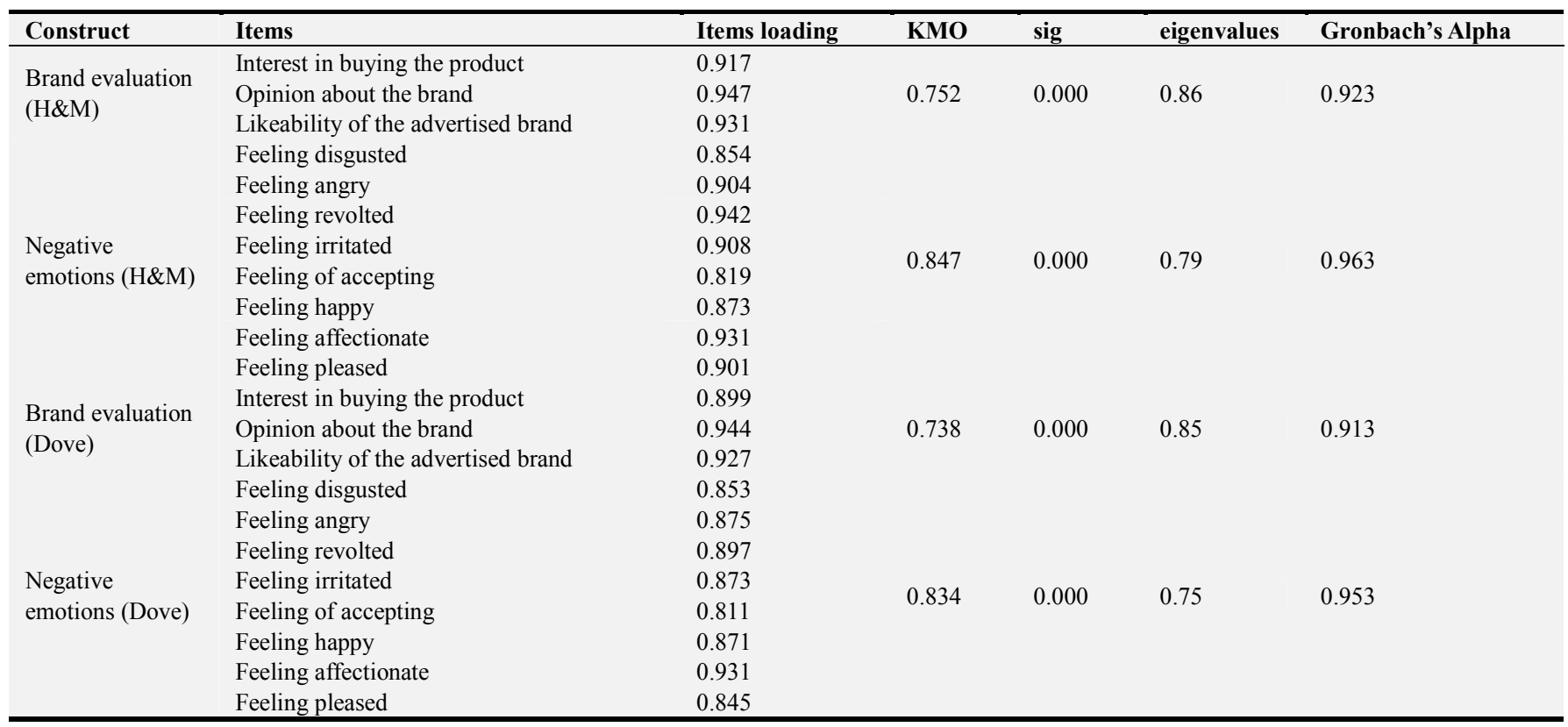

Table 1 shows the reliability and significance of the factor analysis for the two constructs; brand evaluation and negative emotions. Indeed, for H\&M advertisement (1) (see appendix 1), the items constructing brand evaluation show good loading $(>0.7)$. In addition, the KMO coefficient achieved 0.752 is considered acceptable and the reliability coefficient; Gronbach alpha is considered high as it reached 0.923 . Henceforth, the items formulate very well the concept of brand evaluation. As far as the construct of negative emotions is concerned, the latter shows good KMO coefficient (0.847) and the factor analysis is significant $(\mathrm{p}=0.000<0.05)$. Besides, the items loadings are higher than the accepted level which is set at 0.7 [12]. Also, the items have good reliability coefficient which is greater than the threshold level set at 0.7 [12]. Therefore, the 8 items reflect very well the concept of negative emotions. For the Dove advertisement (2) (see appendix), the factor analysis shows good results. In fact, the items formulating brand evaluation show good loading (above 0.7), the KMO equals 0.738 and the test of the feasibility of using factor analysis is significant $(p=0.000<0.05)$. The reliability coefficient is also high as it reached 0.913 which is above the threshold level of 0.7 [12]. The construct of brand evaluation for Dove advertisement has, therefore, good reliability. For the construct negative emotions, the results in table 1 show significance and acceptable KMO coefficient which reached 0.834 . In addition, the items have good reliability as alpha coefficient achieved 0.953. The results of the other two advertisements using visual metaphor in H\&M and Dove advertisements are shown below.

Table 2. Factor analysis results.

Advertisement 1: H\&M and Dove advertisements using metaphorical visualization on marginalized models

\begin{tabular}{|c|c|c|c|c|c|c|}
\hline Construct & Items & Items loading & KMO & sig & eigenvalues & Gronbach's Alpha \\
\hline \multirow{3}{*}{$\begin{array}{l}\text { Brand evaluation } \\
(\mathrm{H} \& \mathrm{M})\end{array}$} & Interest in buying the product & 0.927 & \multirow{3}{*}{0.759} & \multirow{3}{*}{0.000} & \multirow{3}{*}{0.88} & \multirow{3}{*}{0.934} \\
\hline & Opinion about the brand & 0.951 & & & & \\
\hline & Likeability of the advertised brand & 0.941 & & & & \\
\hline \multirow{4}{*}{$\begin{array}{l}\text { Negative } \\
\text { emotions (H\&M) }\end{array}$} & Feeling disgusted & 0.822 & \multirow{4}{*}{0.854} & \multirow{4}{*}{0.000} & \multirow{4}{*}{0.84} & \multirow{4}{*}{0.972} \\
\hline & Feeling angry & 0.949 & & & & \\
\hline & Feeling revolted & 0.943 & & & & \\
\hline & Feeling irritated & 0.878 & & & & \\
\hline
\end{tabular}




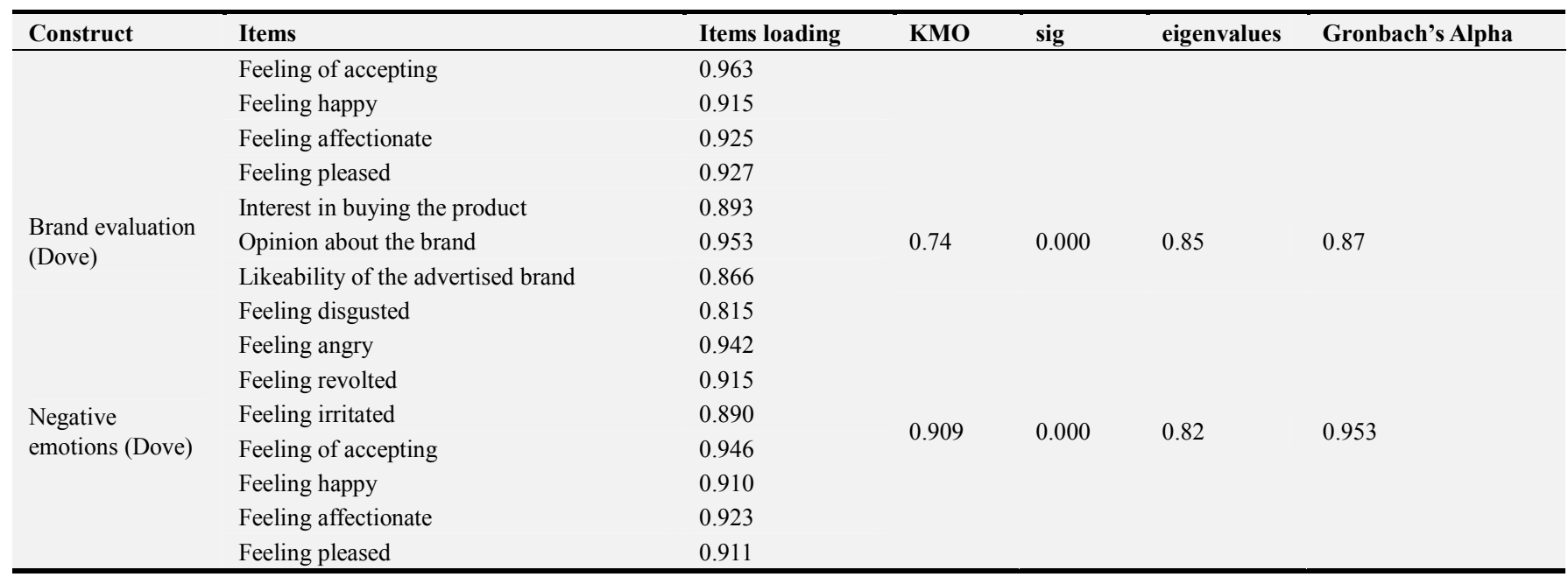

According to table 2, the concepts of brand evaluation and negative emotions for the two advertisements, using metaphor on the marginalized portrayals, show acceptable indices. In fact, the items related to brand evaluation for H\&M advertisements (3) (see appendix) highlights a KMO equals to 0.759 and the Bartlett's test is significant which indicates that the use of factor analysis in this case is significant. Besides, the three items have good reliability coefficient which is equal to 0.934 . In addition, negative emotions demonstrate good reliability as alpha equals 0.972 . Similarly, KMO coefficient is acceptable as it reached 0.854 with a significant test $(\mathrm{p}=0.000<0.05)$ which indicates that factor analysis is adequate for this construct. Moving to Dove advertisement, the results are significant for both constructs. Indeed, brand evaluation has a KMO coefficient equals to 0.74 and an alpha coefficient equals to 0.87 which reflects good cohesion between the items of the concept brand evaluation. Last but not least, the items of negative emotions reached a KMO coefficient equals to 0.909 and a reliability alpha coefficient equals to 0.953 . The feasibility of factor analysis is also reached because the test is significant $(\mathrm{p}=0.000<0.005)$.

From the results above, the constructs of brand evaluation and negative emotions for the 4 advertisements are onedimensional and their items have good internal consistency. The second step in analyzing the data consists in testing the effect of the use of marginalized groups on the brand evaluation and viewers' negative emotions. It also deals with the use of metaphor on marginalized models and its impact on the way viewers' evaluate the brand and on their negative emotions. Below, the statistical tool used and the results of the second analysis is presented.

\subsection{Paired Sample T-test}

In order to detect the difference between the use of marginalized groups and the integration of visual metaphor on these marginalized models, a paired sample t-test was used in order to show the means difference between advertisement using only marginalized models and advertisements using visual metaphor and marginalized models.

Table 3. Paired sample t-test.

H\&M advertisement

\begin{tabular}{llll}
\hline Type of effect & Variables & Means & t-test \\
\hline Marginalized model & Brand evaluation & 6.07 & 15.70 \\
Metaphorical visualization of marginalized model & Brand evaluation & 1.90 & 0.000 \\
Marginalized model & Negative emotions & 6.19 & 16.72 \\
Metaphorical visualization of marginalized model & Negative emotions & 1.89 & 0.000 \\
\hline
\end{tabular}

Table 3 shows that the paired sample t-test is significant. In fact, the means are different between the two types of advertisements. Indeed, for the first H\&M advertisement which uses the black model (marginalized portrayal), viewers' reacted favourably and positively when evaluating the brand $(\mathrm{M}=6.07)$, wherears H\&M advertisement, which uses metaphorical visualization on the black boy, shows unfavorouble and negative brand evalutaion $(\mathrm{M}=1.90)$. More importatnly, the $\mathrm{t}$-test shows significance $(\mathrm{t}=0.000<0.005)$ which points out that the means are different between the two types of H\&M commercials. Henceforth, the use of marginalized model engenders a favaourable reaction when evaluating the brand and less negative emotions. However, metaphorical visualisation leads to a very unfavourable viewers' reaction as the viewers evaluated the brand unfavourably and expressed more negative emotions. As far as the paired sample t-test of Dove advertisements is concered, the results are shown in table 4 . 
Table 4. Paired sample t-test.

Dove advertisement

\begin{tabular}{|c|c|c|c|c|}
\hline Type of effect & Variables & Means & t-test & significance \\
\hline Marginalized model & Brand evaluation & 6.25 & 15.34 & 0.000 \\
\hline Metaphorical visualization of marginalized model & Brand evaluation & 1.70 & & \\
\hline Marginalized model & Negative emotions & 6.13 & 16.86 & 0.000 \\
\hline Metaphorical visualization of marginalized model & Negative emotions & 1.89 & & \\
\hline
\end{tabular}

According to table 4, the means are different between the two types of Dove advertisements. In fact, the first advertisement using marginalized group, the viewers evaluated the brand more favourably $(\mathrm{M}=6.25)$ than advertisement using visual metaphor on marginalized model $(\mathrm{M}=1.70$. Also, table 4 shows that the t-test between the two advertisements shows significant result for the aforementioned variable $(p=0.000<0.005)$. As far as the variable negative emotions is concerned, the findings point out positive emotions $(\mathrm{M}=6.13)$ for Dove advertisement using the black woman and more negative emotions $(\mathrm{M}=1.89)$ for the advertisement using metaphorical visualization. The paired sample t-test of this variable is also significant $(p=0.000<0.005)$. Therefore, using metaphorical visualization on marginalized models has a significant effect on the viewers' reaction as this effect leads to negative emotions and unfavorable evaluation for the brand.

The results in tables 3 and 4 lead to the acceptance of hypotheses 1 and 2 . In fact, the use of marginalized model has a positive effect on the brand evaluation and leads to positive emotions for the viewers. Hypotheses 3 and 4, however, are rejected because metaphorical visualization employed on the marginalized models lead to negative brand evaluation and negative emotions. In what follows, a discussion of these findings is presented.

\section{Discussion}

The data manipulation show that there are significant results between advertisements using only marginalized models and the integration of visual metaphor on these models. Starting with H\&M advertisement, the black boy was evaluated favorably by the viewers and engendered positive emotions for the viewers. Similarly, the black, fat and ordinary (no makeup and hair dress) female model used in Dove engendered favorable brand evaluation and positive emotions. The two first hypotheses are therefore accepted. In other words, using non-traditional models is welcome by the viewers and leads to positive brand evaluation and emotions. This result disagrees with [4], finding that show viewers' negative reactions towards advertisements using cues which are different from the target audience's schema. Besides, this finding partially agrees with [1], who showed that advertisements picturing homosexual parents elicit two contradictory reactions. The results of the aforementioned researcher showed that marginalized models lead to a greater recall and attention (positive reaction) but require higher cognitive efforts because they contain portrayals which are inconsistent with the customers' existing schema (negative reaction). However, the acceptance of the two first hypotheses agrees with the findings of [18], who showed that the use of marginalized models has a positive effect on the viewers' reaction towards the brand. The positive reaction, however, needs to be in the same line with the schema. The positive reaction engendered by Tunisian viewers towards the use of marginalized models could be explained by the fact that Tunisians are becoming more open and free towards the stereotypes and prejudices towards black people. In fact, many Tunisian viewers are becoming more socially responsible and engaged as they are welcoming the use of marginalized groups in advertisements. In addition, many brands are more interested in investing on marginalized groups to avoid monotony and standardization in their advertisements. It is very common for Tunisian brands to use old people, ordinary persons, and funny portrayals in order to create higher attention and recall. The second main finding in this study concerns the effect of using visual metaphor on marginalized models. It has been shown that there is a negative impact on brand evaluation and viewers' emotion when H\&M and Dove use metaphor to dehumanize and marginalize the black models. This result reveals that viewers are aware about the misuse of metaphor and on using nontraditional models to discriminate. In other words, many viewers understood the transformation of black women into white women, in the context of Dove skin-cleansing product, to be a racist message which transmits the idea that white skin is clean and black skin as dirty. Henceforth, Tunisian viewers welcome non-traditional groups in advertisements but when a visual metaphor is used on these non-traditional models with a violation of the viewers' schemas, the advertisements will be rejected the viewers will develop negative emotions towards the brand. Besides, [17, 20] explained these negative emotions and evaluation by the fact that viewers become frustrated with their incapacity to match the incongruity of the visual metaphor used on marginalized portrayals. As a result, they react negatively, which will affect brand evaluation and perception. Therefore, Brands should take into consideration how positive models of traditionally marginalized groups may be perceived when other cultural and societal factors are considered.

\section{Conclusion}

To conclude, brands are recommended to include marginalized group in their advertisements in order to create change and engagement. The use of marginalized group, however, should be dealt with carefully as advertisers need to take into consideration certain social and cultural factors that 
can affect viewers' reaction towards the brand. Creating incongruity in non-traditional model using visual metaphor and other tools should not offend viewers' core values, beliefs and schemas because it can affect their evaluation and emotion towards the brand.

\section{Limitations and Future Studies}

It is acknowledged that there are some limitations in this study. First of all, the data of this study was collected through a questionnaire without using other tools like observation and interviews. It would be more interesting to include qualitative data in future studies. Secondly, it is recommended to increase the sample size in future studies to validate the results. Last but not least, future studies can include other factors such as identity threat and to what extent can viewers accept or positively react to an advertisement that violates his/her schemas and what type of schemas that engender more effect on the viewers' reaction.

\section{Appendix}

\section{Questionnaire}

Dear students,

Could you please fill this questionnaire about "metaphorical visualization of marginalized groups in print advertisement". You need to observe H\&M and Dove advertisements and then answer the questions below each commercial. Your answers will stay anonymous and will serve only this piece of research.

Thank you in advance!!

Part 1

Personal information

Are you? Female

What is your age?

What is your level of education? $\quad 1^{\text {st }}$ year

Male 0

What is your level of educatio
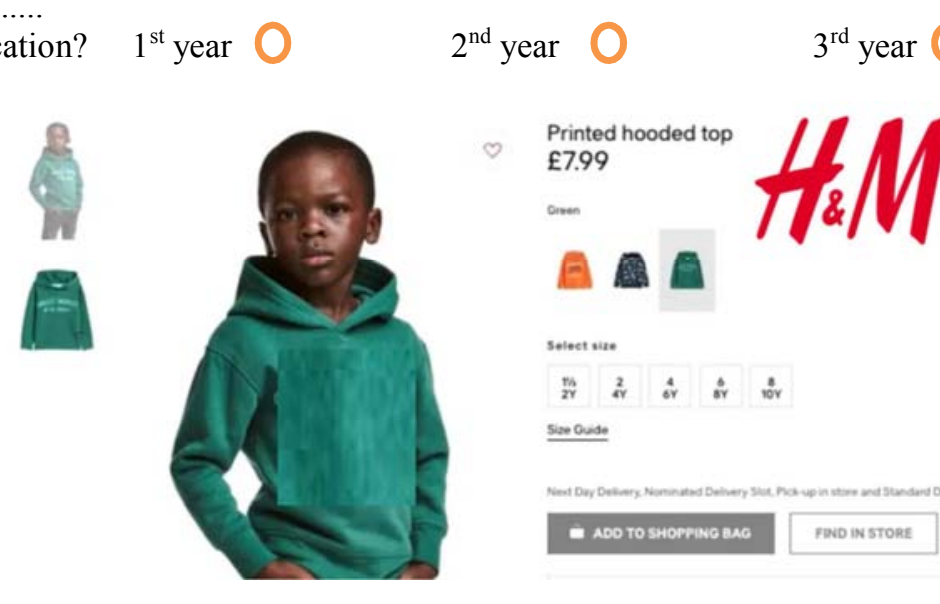

H\&M advertisement (1).

After observing H\&M advertisement (1):

1. $\mathrm{M} y$ interest in buying $\mathrm{H} \& \mathrm{M}$ products is

Low interest

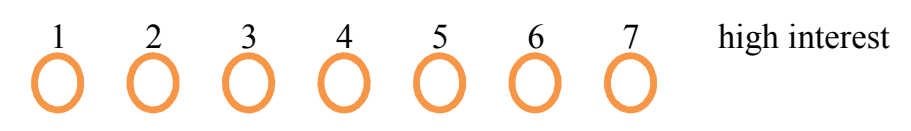

2. I think that $\mathrm{H} \& \mathrm{M}$ brand is:

Very bad

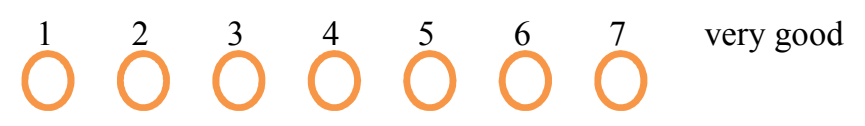

3. My attitude towards H\&M brand is that $\mathrm{I}$ :

I dislike it very much

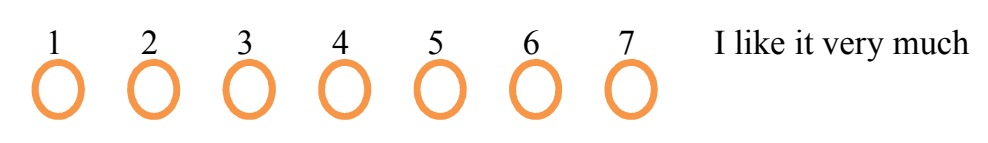

4. I feel disgusted towards H\&M brand:

Very much

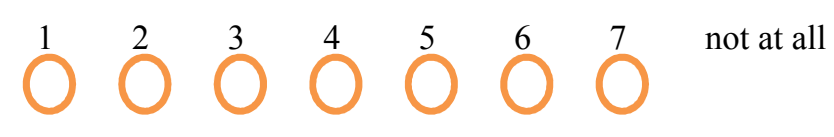


5. I feel angry towards H\&M brand:

Very much

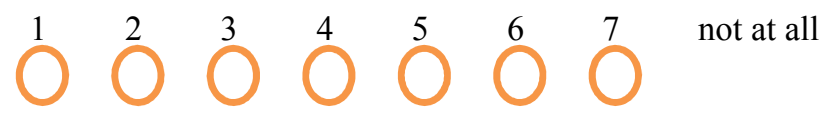

6. I feel revolted towards $\mathrm{H} \& \mathrm{M}$ brand:

Very much

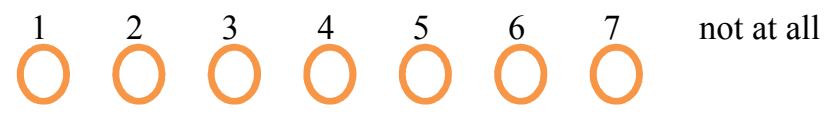

7. I feel irritated towards H\&M brand:

Very much

$$
10^{2} 0^{3} 0^{4} 0^{5} 0^{6} 0^{7} \text { not at all }
$$

8. I accept $H \& M$ advertisement:

Not at all

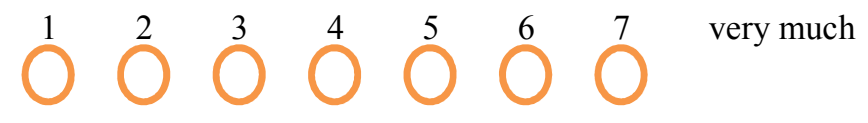

9. I feel happy about H\&M advertisement:

Not at all

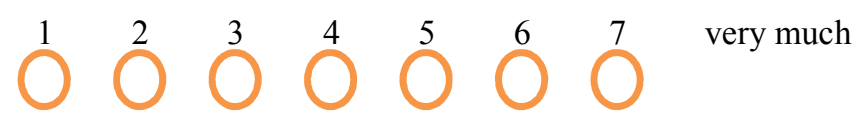

10. I feel affectionate about $\mathrm{H} \& \mathrm{M}$ advertisement:

Not at all

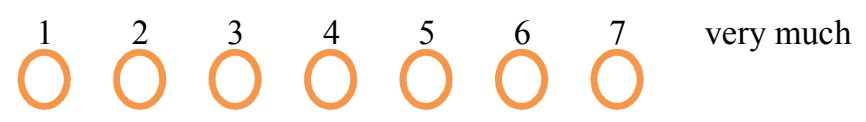

11. I feel pleased about H\&M advertisement:

Not at all
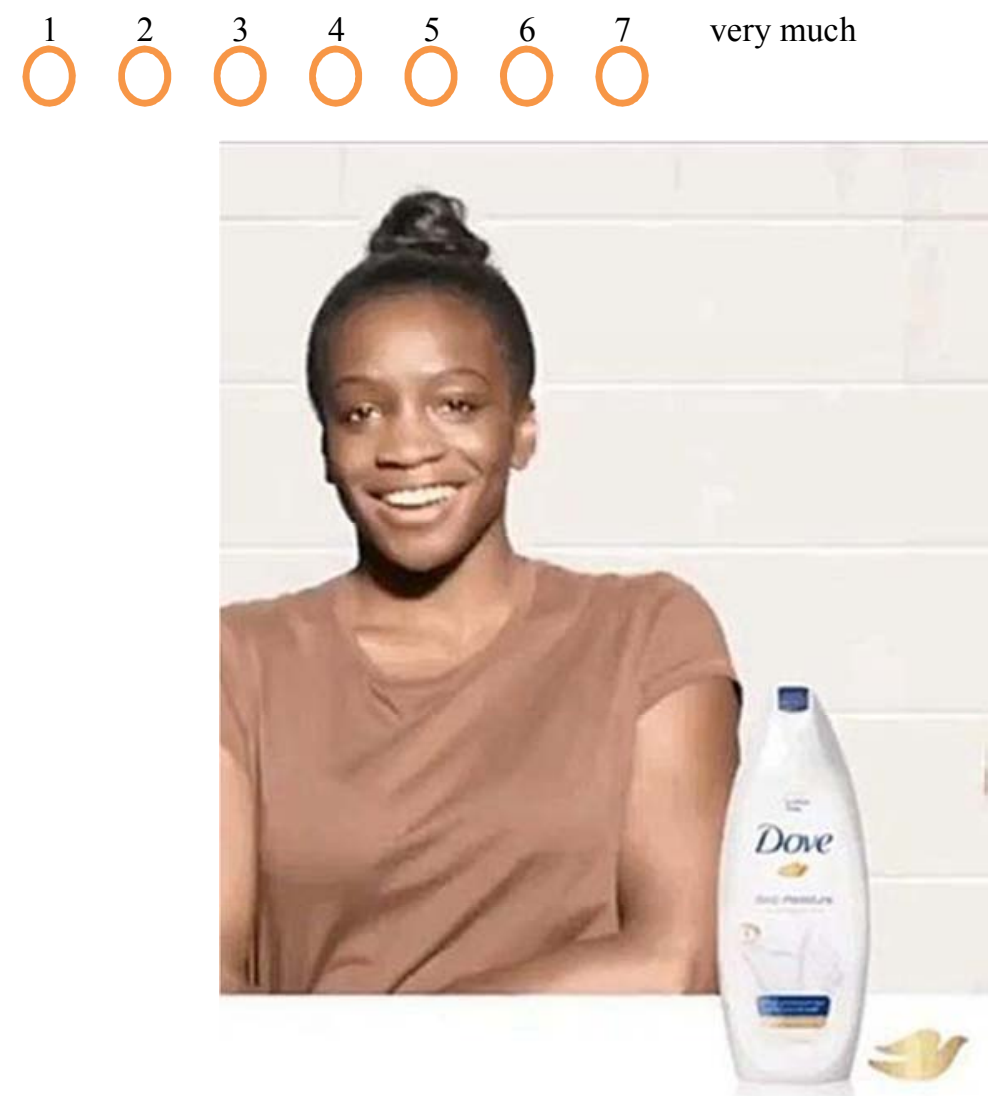

Dove advertisement (2). 
After observing Dove advertisement (2):

12. $\mathrm{M}$ y interest in buying Dove products is

Low interest $13030^{2} O^{5} O^{6} O^{7}$ high interest

13. I think that Dove brand is:

Very bad $12 O^{2} O^{3} O^{5} O^{6} O^{7}$ very good

14. My attitude towards Dove brand is that I:

I dislike it very much

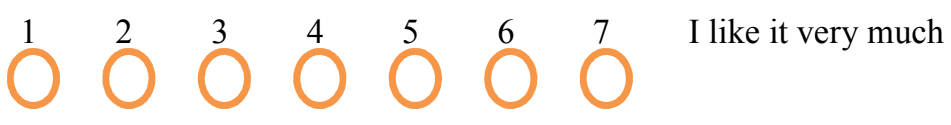

15.I feel disgusted towards Dove brand:

Very much

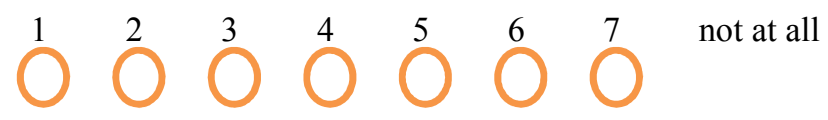

16.I feel angry towards Dove brand:

Very much

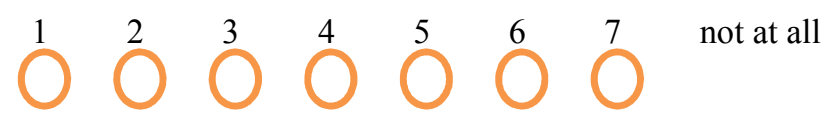

17. I feel revolted towards Dove brand:

Very much

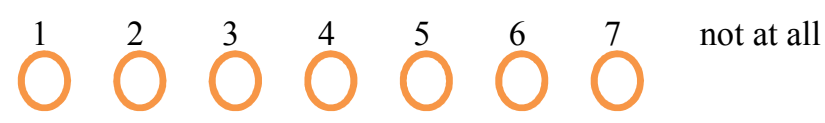

18. I feel irritated towards Dove brand:

Very much

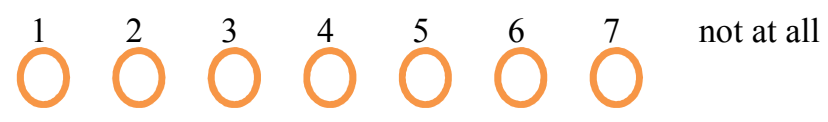

19. I accept Dove advertisement:

Not at all

$$
10^{2} 0^{3} 0^{4} 0^{5} 0^{6} 0^{7} \text { very much }
$$

20.I feel happy about Dove advertisement:

Not at all

$$
10^{2} 0^{3} \bigcirc^{4} \bigcirc^{5} \bigcirc^{6} \bigcirc^{7} \text { very much }
$$

21.I feel affectionate about Dove advertisement:

Not at all

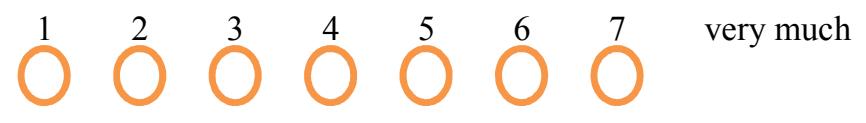

22. I feel pleased about Dove advertisement:

Not at all

Part 2:

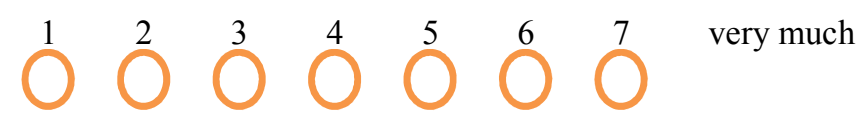




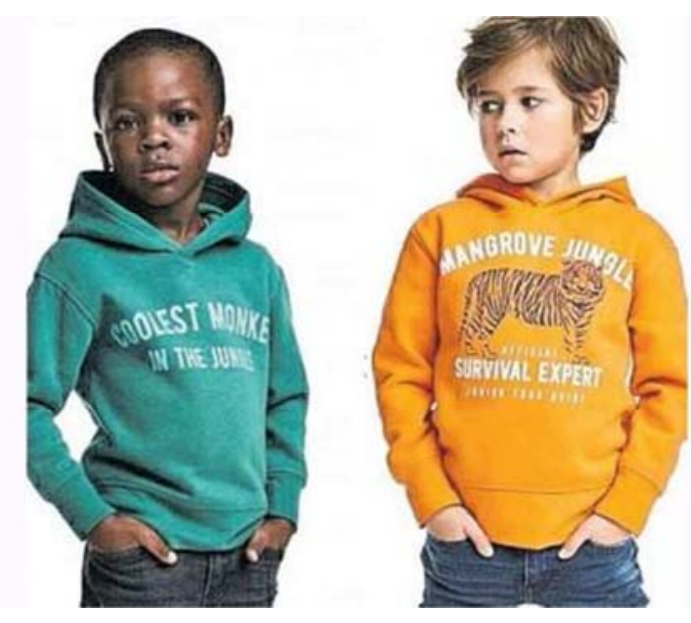

$H \& M$ advertisement (3).

After observing H\&M advertisement (3):

1. $\mathrm{M}$ y interest in buying $\mathrm{H} \& \mathrm{M}$ products is

Low interest

$$
10^{2} 0^{3} \mathrm{O}^{4} \mathrm{O}^{5} \mathrm{O}^{6} \mathrm{O}^{7} \text { high interest }
$$

2. I think that H\&M brand is:

Very bad

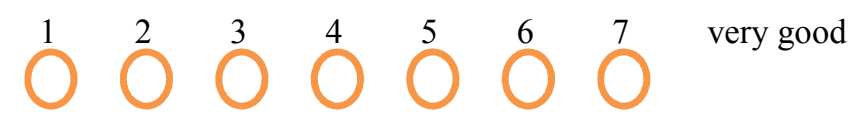

3. My attitude towards H\&M brand is that I:

I dislike it very much

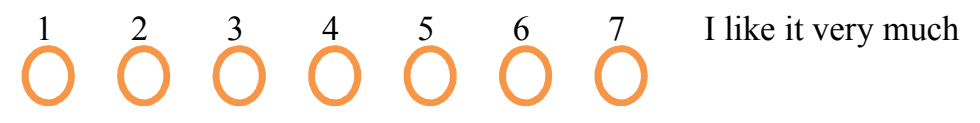

4. I feel disgusted towards H\&M brand:

Very much

$$
10^{2} 0^{3} 0^{4} 0^{5} 0^{6} 0^{7} \text { not at all }
$$

5. I feel angry towards H\&M brand:

Very much $13 O^{2} O^{3} O^{5} O^{6} O^{7}$ not at all

6. I feel revolted towards H\&M brand:

Very much

$$
10^{2} 0^{3} 0^{4} 0^{5} 0^{6} 0^{7} \text { not at all }
$$

7. I feel irritated towards H\&M brand:

Very much

$$
10^{2} 0^{3} 0^{4} 0^{5} 0^{6} 0^{7} \text { not at all }
$$

8. I accept H\&M advertisement:

Not at all

$$
10^{2} 0^{3} \overbrace{}^{4} \bigcirc^{5} \overbrace{}^{6} \bigcirc^{7} \text { very much }
$$

9. I feel happy about H\&M advertisement:

Not at all

$$
130^{3} 0^{4} 0^{5} 0^{6} 0^{7} \text { very much }
$$


10.I feel affectionate about H\&M advertisement:

Not at all

$$
10^{2} 0^{3} 0^{4} 0^{5} 0^{6} O^{7} \text { very much }
$$

11.I feel pleased about H\&M advertisement:

Not at all
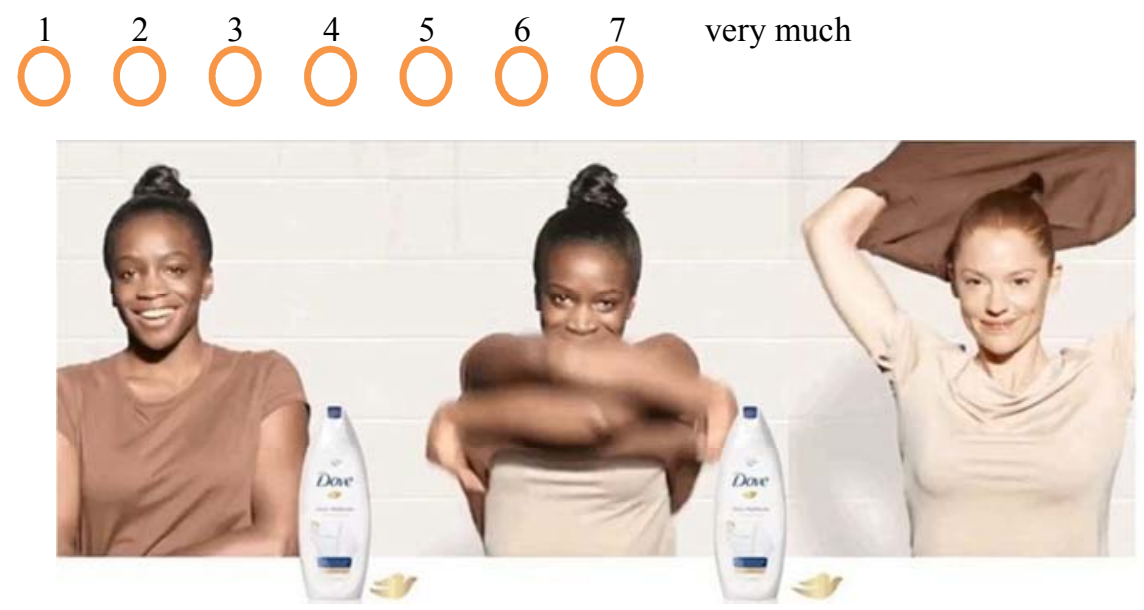

Dove advertisement (4).

After observing Dove advertisement (4):

12. $\mathrm{M}$ y interest in buying Dove products is

Low interest

$$
10^{2} 0^{3} 0^{4} 0^{5} 0^{6} 0^{7} \text { high interest }
$$

13. I think that Dove brand is:

Very bad

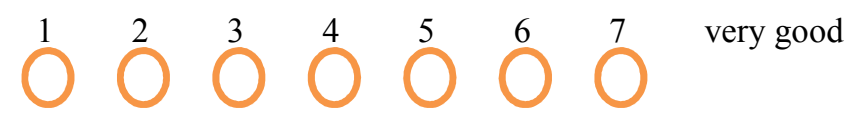

14. My attitude towards Dove brand is that I:

I dislike it very much

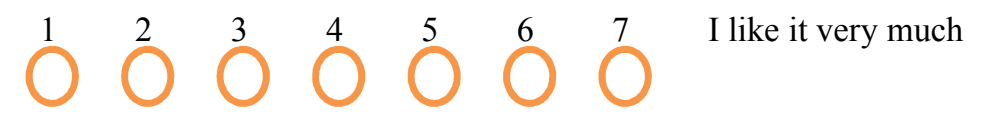

15.I feel disgusted towards Dove brand:

Very much

$$
10^{2} 0^{3} 0^{4} 0^{5} 0^{6} 0^{7} \text { not at all }
$$

16.I feel angry towards Dove brand:

Very much

$$
10^{2} 0^{3} 0^{4} 0^{5} 0^{6} 0^{7} \text { not at all }
$$

17. I feel revolted towards Dove brand:

Very much

$$
10^{2} 0^{3} 0^{4} 0^{5} 0^{6} 0^{7} \text { not at all }
$$

18. I feel irritated towards Dove brand:

Very much

$$
10^{2} 0^{3} 0^{4} 0^{5} 0^{6} 0^{7} \text { not at all }
$$

19. I accept Dove advertisement: 
Not at all

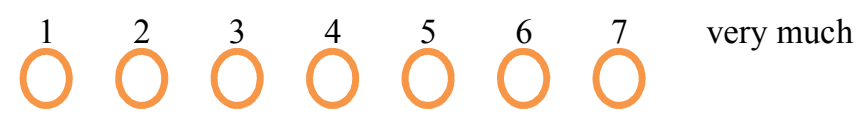

20.I feel happy about Dove advertisement:

Not at all

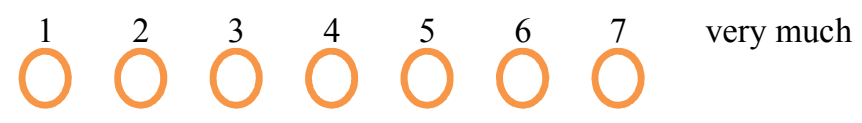

21.I feel affectionate about Dove advertisement:

Not at all

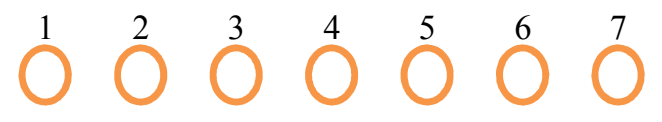

very much

22.I feel pleased about Dove advertisement:

Not at all

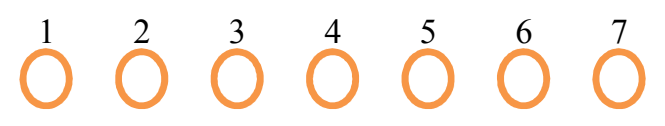

very much

parent families. Group Processes \& Intergroup Relations, 20 (1), 109-124.

\section{References}

[1] Angelini, J. R., \& Bradley, S. D. (2010). Homosexual imagery in print advertisements: Attended, remembered, but disliked. Journal of homosexuality, 57 (4), 485-502.

[2] Bailey, A. A. (2006). A year in the life of the AfricanAmerican male in advertising: A content analysis. Journal of Advertising, 35 (1), 83-104.

[3] Ballings, M., McCullough, H., \& Bharadwaj, N. (2018). Cause marketing and customer profitability. Journal of the Academy of Marketing Science, 46 (2), 234-251.

[4] Bettencourt, B. A., Dill, K. E., Greathouse, S. A., Charlton, K., \& Mulholland, A. (1997). Evaluations of ingroup and outgroup members: The role of category-based expectancy violation. Journal of experimental social psychology, 33 (3), 244-275.

[5] Bhat, S., Leigh, T. W., \& Wardlow, D. L. (1998). The effect of consumer prejudices on ad processing: Heterosexual consumers' responses to homosexual imagery in ads. Journal of Advertising, 27 (4), 9-28.

[6] Bonchek, M. \& France, C. (2016). Build your brand as a relationship. Harvard Business Review. Retrieved from https://hbr.org/2016/05/build-your-brand-as-a-relationship.

[7] Ellen, P. S., Webb, D. J., \& Mohr, L. A. (2006). Building corporate associations: Consumer attributions for corporate socially responsible programs. Journal of the academy of Marketing Science, 34 (2), 147-157.

[8] Fiske, S. T., \& Linville, P. W. (1980). What does the schema concept buy us?. Personality and social psychology bulletin, 6 (4), 543-557.

[9] Jaffe, C. (2015). How advertising has become an agent of social change. Retrieved from https://medium.com/@moonstorming/how-advertising-hasbecome-an-agent-of-social-change-148aa0ef303a.

[10] Kille, D. R., \& Tse, C. T. (2017). Whose family fits? Categorization and evaluation of same-sex and cross-race-

[11] Fournier, S. (1998). Consumers and their brands: Developing relationship theory in consumer research. Journal of consumer research, 24 (4), 343-373.

[12] Dash, M., \& Malhotra, N. K. (2016). Marketing Research an Applied Orientation. Indian Institute of Management Lucknow.

[13] McQuarrie, E. F., \& Phillips, B. J. (2005). Indirect persuasion in advertising: How consumers process metaphors presented in pictures and words. Journal of advertising, 34 (2), 7-20.

[14] Meyers-Levy, J., \& Tybout, A. M. (1989). Schema congruity as a basis for product evaluation. Journal of consumer research, 16 (1), 39-54.

[15] Mzoughi, N., \& Abdelhak, S. (2011). The impact of visual and verbal rhetoric in advertising on mental imagery and recall. International Journal of Business and Social Science, 2 (9).

[16] Paharia, N., Avery, J., \& Keinan, A. (2014). Positioning brands against large competitors to increase sales. Journal of Marketing Research, 51 (6), 647-656.

[17] Peracchio, L. A., \& Tybout, A. M. (1996). The moderating role of prior knowledge in schema-based product evaluation. Journal of consumer research, 23 (3), 177-192.

[18] Ruggs, E. N., Stuart, J. A., \& Yang, L. W. (2018). The effect of traditionally marginalized groups in advertising on consumer response. Marketing Letters, 29 (3), 319-335.

[19] Sandıkc1, Ö., \& Ekici, A. (2009). Politically motivated brand rejection. Journal of Business Research, 62 (2), 208-217.

[20] Torelli, C. J., \& Ahluwalia, R. (2012). Extending culturally symbolic brands: A blessing or a curse?. Journal of Consumer Research, 38 (5), 933-947.

[21] Weigel, D. J. (2008). The concept of family: An analysis of laypeople's views of family. Journal of Family Issues, 29 (11), 1426-1447.

[22] Zmuda, N. (2014). Ad campaigns are finally reflecting diversity of U.S. Advertising Age. Retrieved from http://adage.com/article/news/ad-campaigns-finally-reflectsdiversity-u-s/292023/. 